Gut, 1987, 28, 583-587

\title{
Effects of exercise on mesenteric blood flow in man
}

\author{
M I QAMAR AND A E READ \\ From the University Department of Medicine, Bristol Royal Infirmary, Bristol
}

SUmmary Transcutaneous Doppler ultrasound was used to assess the effects of exercise on both fasting and postprandial superior mesenteric artery blood flow. After treadmill exercise (speed 5 $\mathrm{km} / \mathrm{h}$, gradient $20 \%$, duration $15 \mathrm{~min}$ ) in 16 subjects, superior mesenteric artery blood flow decreased by $43 \%$ immediately after the end of the exercise and by $29 \%$ at five minutes and $24 \%$ at 10 minutes postexercise. The superior mesenteric artery blood flow response to a combination of a treadmill exercise and a liquid meal in 15 volunteers was significantly smaller at five minutes from the end of the stimuli, than the response to the meal alone $(15$ controls $)(635 \pm 51 \mathrm{ml} / \mathrm{min} v 846 \pm 72$ $\mathrm{ml} / \mathrm{min})(\mathrm{p}<0 \cdot(025)$, but not different at any other time. Thus exercise reduces mesenteric blood flow in both the fasting and postprandial state in normal subjects.

In 1939 Kats and Robdard' described the splanchnic circulation as a 'blood giver of the circulation' and pointed out that the splanchnic circulation may play a major role in overall cardiovascular regulation. Since then several investigations of splanchnic and mesenteric blood flow during stressful conditions such as exercise have been carried out in man and animals.' The results of the exercise studies are conflicting, however. In man, splanchnic blood flow has been shown to be reduced during exercise by several investigators. ${ }^{3-1}$ Blood flow to the abdominal viscera is reduced by $20-30 \%$ of the resting value during maximal exercise in young healthy subjects, irrespective of their state of training or absolute aerobic capacity.' In contrast canine superior mesenteric artery blood flow (SMABF) remained stable during exercise. ${ }^{x-11}$ Exercise also did not affect SMABF in baboons. ${ }^{12}$

The postprandial increment in SMABF was reported not to be compromised in exercising dogs." "' Thus in dogs exercise does not appear to affect mesenteric blood flow either during the fasting state or during digestion. Although a reduction in human splanchnic blood flow has been confirmed repeatedly during exercise, no studies concerning human

Address for correspondence: Dr M I Uamar, Department of Medicine. Bristol Royal Infirmary. Bristol.

Received for publication 16 September 1986
SMABF per se either in the fasting or postprandial state, seem to have been reported.

The aim of the present investigation was to assess the effect of exercise on SMABF in healthy subjects in both the fasting and postprandial state using a transcutaneous Doppler ultrasound method..$^{14}$

\section{Methods}

SUBJECTS

Sixteen healthy volunteers, eight men, eight women, aged 19-52 years (mean 25.6 years) with body weights ranging from $52-86 \mathrm{~kg}$ (mean $65.9 \mathrm{~kg}$ ) were studied. Their normal physical activity varied from active to sedentary; nine were involved in sporting activities, the rest were not. The investigation was carried out under quiet conditions in an ambient temperature of $21 \pm 1^{\circ} \mathrm{C}$. Subjects were fasted for 12 hours and before examination were rested for 30 minutes in the supine position. A 'resting' Doppler ultrasound recording of the superior mesenteric artery was taken at the end of this period. Exercise was carried out on a treadmill (Cardio exercise treadmill: Quinton Instruments, Seattle, Washington, USA). Each subject walked for a period of 15 minutes at $5 \mathrm{~km} / \mathrm{h}$ up a $20 \%$ incline. As soon as the treadmill was switched off, the subject returned to the examination couch and an immediate Doppler ultrasound recording was carried out. This was 
repeated five, 10,15 , and 30 minutes from the end of the exercise.

The combined effect of exercise and a meal was investigated in a further group of 15 healthy volunteers ( 10 men, five women) with a mean age of 25.5 years (range 19-36 years). Fifteen healthy volunteers matched for age and sex, 10 men, five women, aged 21-39 years (mean 26 years) were used as a control group.

Superior mesenteric artery blood flow was first recorded in the resting and fasting state in both groups and serially for one hour after treadmill exercise ( $5 \mathrm{~km} / \mathrm{h}$ up a $20 \%$ incline for 15 minutes) and a liquid meal in the first group and after the meal alone in the control group. Over the first 10 minutes of the exercise period a liquid meal was ingested.

Superior mesenteric artery blood flow was recorded immediately after the end of exercise, that is five minutes after the end of ingestion of the meal. Subsequent recordings were performed at $10,15,30$, 45 , and 60 minutes from the end of the meal. Identical recordings were done in the control group (meal alone).

The meal was made from one sachet of commercially available strawberry flavoured 'Build up' (Carnation) mixed with $400 \mathrm{ml}$ milk ( $390 \mathrm{~K} \mathrm{cal}, 21.6 \mathrm{~g}$ protein, $15.4 \mathrm{~g}$ fat and $41.3 \mathrm{~g}$ carbohydrate).

Superior mesenteric artery blood flow was measured by using a transcutaneous Doppler ultrasound method, details of which have been described earlier ${ }^{13}$ and here are described briefly. A duplex scanner, which is a pulsed Doppler flowmeter associated with a real time imager, was used. The real time imaging system was used to visualise the superior mesenteric artery and this allowed the placement of the Doppler sample volume within the lumen of the artery so as to obtain the Doppler shift signals. Real time imaging was also used to measure both the diameter of the artery and the angle of insonation - that is, between the directions of the Doppler beam and the artery. Signals were analysed using a spectrum analyser (Radionics 8000) and a computer (Apple). The instantaneous average velocity over the cardiac cycle was then calculated and blood flow volume was derived by knowing the cross sectional area of the vessel.

The mean, standard deviation and standard error of the mean (SEM) were used for the calculation of the data; Student's $t$ test was used for paired data.

\section{Results}

EFFECT OF EXERCISE ON SMABF IN THE FASTING STATE

The mean value (SEM) of the resting SMABF was $555 \pm 30 \mathrm{ml} / \mathrm{min}(\mathrm{n}=16)$. The mean $( \pm$ SEM $)$ of the

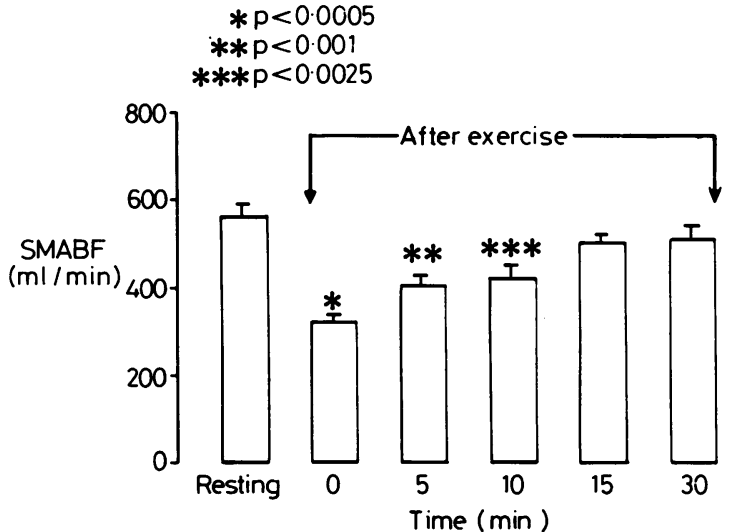

Fig. 1 Mean values \pm standard error of the mean of the superior mesenteric artery blood flow (SMABF) at rest and 0-30 minutes after the end of treadmill exercise in 16 normal subjects.

post exercise values are shown in Figure 1. Immediately after the end of the exercise $(0 \mathrm{~min}) \mathrm{SMABF}$ had decreased by $43 \%$ to $319 \pm 21 \mathrm{ml} / \mathrm{min}(\mathrm{p}<0.0005)$ (Fig. 2). Mean SMABF was below the pre-exercise control level by $29 \%(p<0.001)$ at 5 and $24 \%$ $(p<0.0025)$ at 10 minutes from the end of the exercise (Fig. 2). Flow was still reduced by $10 \%$ at 15 and $9 \%$ at 30 minutes after exercise, but these differences no longer achieved statistical significance (Fig. 1).

COMBINED EFFECT OF EXERCISE AND A MEAL ON THE SMABF

The mean values $( \pm$ SEM) of SMABF in the 15 subjects of the exercise plus meal group, and in the 15 controls (meal alone) are shown in the Table. Five minutes from the end of the meal ( 0 minutes after the end of exercise) the mean SMABF had increased by

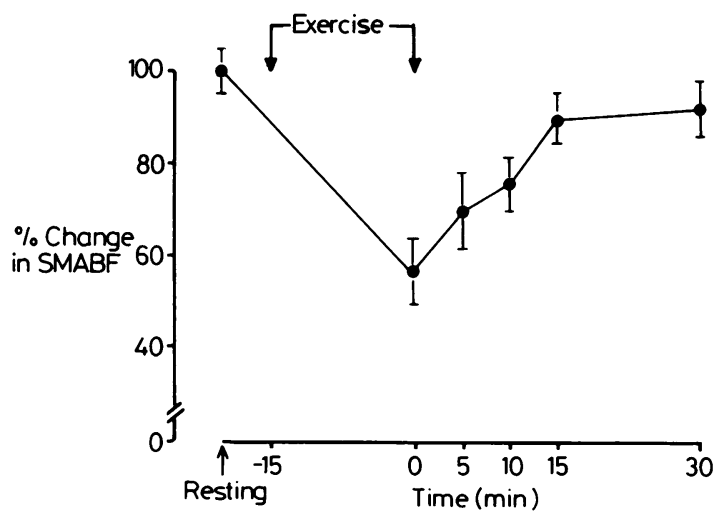

Fig. 2 Percentage change in superior mesenteric artery blood flow (SMABF) after treadmill exercise in 16 normal subjects. 
Table Superior mesenteric artery blood flow (SMABF) at rest and 5-60 min after taking a liquid meal and exercise and $a$ liquid meal alone

\begin{tabular}{|c|c|c|c|c|}
\hline \multirow[b]{2}{*}{ Time } & \multicolumn{2}{|c|}{$\begin{array}{l}S M A B F(\mathrm{ml} / \mathrm{min}) \\
\text { mean values } \pm S E M\end{array}$} & \multicolumn{2}{|l|}{ t test } \\
\hline & $\begin{array}{l}\text { Meal+exercise } \\
(n=15)\end{array}$ & $\begin{array}{l}\text { Meal alone } \\
\text { controls } \\
(n=15)\end{array}$ & tvalue & $p$ \\
\hline Resting & $513 \pm 34$ & $523 \pm 4()$ & $0 \cdot 188$ & NS \\
\hline Postprandial & - & - & - & - \\
\hline $5 \mathrm{~min}$ & $633 \pm 51$ & $846 \pm 72$ & $2 \cdot 415$ & $<0.025$ \\
\hline $10 \mathrm{~min}$ & $750 \pm 62$ & $812 \pm 64$ & 0.698 & NS \\
\hline $15 \mathrm{~min}$ & $730 \pm 48$ & $814 \pm 42$ & 1.296 & NS \\
\hline $30 \mathrm{~min}$ & $728 \pm 53$ & $710 \pm 46$ & $0 \cdot 263$ & NS \\
\hline $45 \mathrm{~min}$ & $664 \pm 54$ & $676 \pm 48$ & 0.168 & NS \\
\hline 6() $\min$ & $571 \pm 54$ & $628 \pm 42$ & 0.932 & NS \\
\hline
\end{tabular}

$23 \%$ to $633 \pm 51 \mathrm{ml} / \mathrm{min}$ in the exercise plus meal group (Fig. 3). This was followed by an increment of $46 \%$ $(750 \pm 62 \mathrm{ml} / \mathrm{min})(\mathrm{p}<0.0025)$ at $10,42 \%(730 \pm 48$ $\mathrm{ml} / \mathrm{min})(\mathrm{p}<0 \cdot 0005)$ at $15,42 \%(728 \pm 53 \mathrm{ml} / \mathrm{min})$ $(\mathrm{p}<0.001)$ at 30 and $29 \%(664 \pm 54 \mathrm{ml} / \mathrm{min})(\mathrm{p}<0.025)$ at 45 minutes (Fig. 3). Superior mesenteric artery blood flow at 60 minutes was not statistically different from the resting and fasting level.

Compared with the response to meal alone (controls) the response to the combined stimuli (exercise and meal) was smaller at 5 minutes $(633 \pm 51 \mathrm{ml} / \mathrm{min} v$ $846 \pm 72 \mathrm{ml} / \mathrm{min})(\mathrm{p}<0.025)$ but not different at any other time (Table).

\section{Discussion}

Previous measurements of SMABF during exercise have all been carried out in animals. In man the

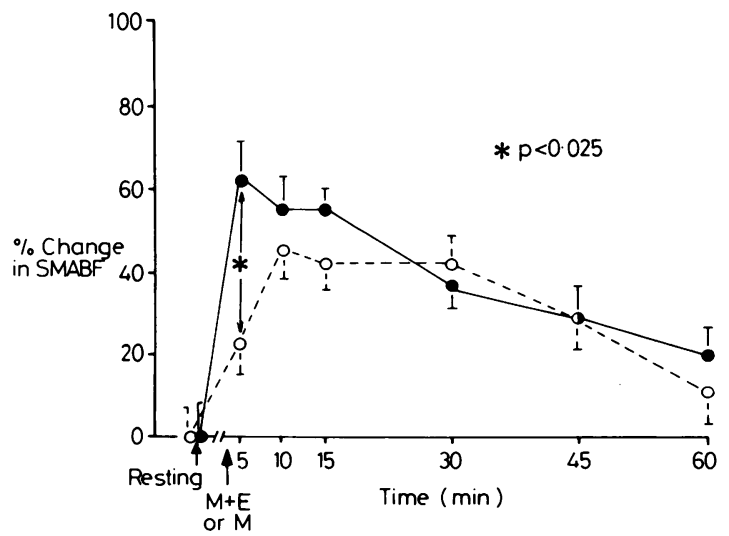

Fig. 3 Changes in superior mesenteric artery blood flow $(S M A B F)$ at the end of a liquid meal with treadmill exercise $(M+E)$ in 15 normal subjects (dotted line) and after a meal only $(M)$ in 15 control subjects (continuous line). splanchnic rather than mesenteric blood flow has been investigated, as methods of measuring the latter are extremely difficult to do in exercising subjects.

In the present study the use of a transcutaneous Doppler ultrasound method allowed pre and postexercise recordings of the SMABF to be carried out. The method is simple, non-invasive, reproducible over both short and long term ${ }^{13}$ and can detect changes in mesenteric blood flow after physiological stimuli such as feeding. ${ }^{1+}$ The in vitro calibration has indicated an acceptable level of accuracy of the method. ${ }^{15}$ Interference by the respiratory and/or vessel wall movements (wall thump), however, which are accentuated during and immediately after exercise, could affect the accuracy of measurements. Respiratory movements were minimised by asking the subjects to stop breathing during the recordings, and the problem of the vessel wall movement was reduced by low pass filtering of the Doppler shift signals.

The results of the present studies clearly show that exercise interfered with SMABF in both the fasting and postprandial state. In fasting subjects exercise reduced SMABF by up to $43 \%$ and significantly over the first 10 postexercise minutes. Exercise also interfered with the postprandial SMABF response five minutes after ingestion. Compared with the mesenteric response to the meal alone 'control', meal plus exercise produced a smaller increase in SMABF at five minutes and the maximal increase in SMABF after meal alone was reached earlier than that after both stimuli. Later recordings were not different between the two responses. The measurements of SMABF were taken in the supine position before and after exercise which was carried out in the upright position, so that the response during exercise and the effect of posture remain unclear. It was assumed, however, that the measurements taken immediately after exercise would reflect the response during exercise. Posture appears to have no major influence on the manner in which human splanchnic blood flow is reduced during exercise. ${ }^{16}$ This is probably also true in the case of SMABF. The severity of the exercise was assessed by the graphical method reported by Jones and Campbell ${ }^{17}$ converting the treadmill speed and elevation into an equivalent oxygen uptake and power output. Oxygen uptake of the subjects in the present study was estimated to be $45 \mathrm{ml} / \mathrm{kg} / \mathrm{min}$ and according to body weight the equivalent power output varied from 1100 to $1650 \mathrm{kpm} / \mathrm{min}$ (mean 1330 $\mathrm{kpm} / \mathrm{min}$ ) indicating that the exercise was severe.

The post exercise decrement in fasting SMABF shown in the present investigation supports the reduction in splanchnic blood flow reported in man during exercise. ${ }^{3-6}$ The results are not directly comparable, however, as mesenteric and not splanchnic 
blood flows were measured in these studies. The findings of the present study disagree with the stability of the SMABF during exercise reported in fasted dogs. ${ }^{x-11}$ The reason for these discrepancies seems to be the difference in species. It has been suggested that in normal dogs the sympathetic nervous system under certain stresses is less involved than in man. ${ }^{18}$ Probably this may also be the reason for the stability of mesenteric blood flow in baboons.

The influence of exercise on the postprandial SMABF responses shown in the present study also disagrees with the results of similar investigations in dogs where exercise did not affect postprandial SMABF significantly. ${ }^{\prime \prime \prime}$ The difference in species and experimental conditions are probably the reason for this discrepancy too.

The results of this study support the concept of redistribution of blood flow during exercise and diversion of blood flow from the splanchnic viscera to the working muscles. ${ }^{16}$ The mechanism of this redistribution is still unclear. A number of mechanisms have been suggested for exercise induced splanchnic vasoconstriction. ${ }^{16}$ Reflexes originating from the working muscles are thought to play an important role though the nature of these reflexes is still unclear. ${ }^{16}$ One mechanism would be that the splanchnic vasoconstriction simply reflects generalised increased sympathetic tone during exercise. In working muscles the increase in sympathetic drive could be opposed by the effect of local vasodilator metabolites such as changes in $\mathrm{O}_{2}, \mathrm{CO}_{2}$ or other substances. In view of the results of the present investigation one would speculate that the exercise is better avoided during the immediate postprandial period. This would be particularly important when the meal is a large one and the exercise is severe and performed under risky circumstances such as swimming. The competition between blood flow demands for the working skeletal muscles and the gut might contribute to postprandial drowning. In the present study, however, SMABF was about $300 \mathrm{ml} / \mathrm{min}$. On the other hand the cardiac output is increased to values that may exceed $35 \mathrm{l} / \mathrm{min}$ in exercise. ${ }^{19}$ The large difference between the increase of cardiac output and SMABF makes it unlikely that the postprandial mesenteric hyperaemia is a major factor in drowning. The severity of the exercise and the general cardiovascular state could be other important contributory factors. In patients with cardiovascular disease exercise probably reduces SMABF more than in normal subjects and the occurrence of both stimuli (exercise and digestion) simultaneously might aggravate this state. It has been shown that splanchnic blood flow during exercise in patients with mitral stenosis is reduced to a greater degree than in normal subjects. ${ }^{21}$
In conclusion these studies have shown that exercise reduces $S M A B F$ in both the fasting and postprandial state in normal human subjects. These results are in support of the concept of redistribution of blood flow during exercise, and they may be of clinical importance in some subjects postprandially.

\section{References}

1 Katz LN, Robdard S. The integration of the vasomotor responses in the liver with those in other systemic vessels. J Pharmacol Exp Ther 1939; 67: 407-22.

2 Rowell LB, Johnson JM. Role of the splanchnic circulation in reflex control of the cardiovascular system. In: Shepherd AP, Granger DN, eds. Physiology of the intestinal circulation. New York. Raven Press, 1984: 153-63.

3 Bradley SE. Variations in hepatic blood flow in man during health and disease. N Engl J Med 1949; 240: 45661.

4 Wade OL, Combes B, Childs AW, Wheeler HO, Cournand A, Bradley SE. The effect of exercise on the splanchnic blood flow and splanchnic blood volume in normal man. Clin Sci 1956; 13: 457-63.

5 Bishop JM, Donald KW, Taylor SH, Wormald PN. Changes in arterial-hepatic venous oxygen content difference during and after supine leg exercise. J Physiol (Lond) 1957; 137: 309-17.

6 Rowell LB, Blackmon JR, Bruce RA. Indocyanine green clearance and estimated hepatic blood flow during mild to maximal exercise in upright man. $J$ Clin Invest 1964; 43: 1677-60.

7 Clausen JP. Effect of physical training on cardiovascular adjustments to exercise in man. Physiol Rev 1977; 57: 779-815.

8 Hopkinson BR, Schenk WG. The electromagnetic measurement of liver blood flow and cardiac output in conscipus dogs during feeding and exercise. Surgery 1968; 63; 970-5.

9 Van Citters RL, Franklin D. Cardiovascular performance of Alaska sled dogs during exercise. Circ Res 1969; 24: 33-42.

10 Burns GP, Schenk Jr WG. Effect of digestion and exercise on intestinal blood flow and cardiac output. Arch Surg 1969; 98: 790-4.

11 Fronek K, Fronek A. Combined effect of exercise and digestion on hemodynamics in conscious dogs. $\mathrm{Am} \mathrm{J}$ Physiol 1970; 218: 555-9.

12 Vatner SF. Effects of exercise and excitement on mesenteric and renal dynamics in conscious unrestrained baboons. Am J Physiol 1978; 234: $\mathrm{H} 210-4$.

13 Qamar NI, Read AE, Skidmore R, Evans JM, Wells PNT. Transcutaneous Doppler ultrasound measurement of superior mesenteric artery blood flow in man. Gut 1986; 27: 100-5.

14 Qamar MI, Read AE. Intestinal blood flow [Editorial]. $Q J$ Med 1985; 56: 417-9.

15 Qamar MI, Beard J, Evans J, Skidmore R, Wells PNT, Read AE. Accuracy and errors of non-invasive measurements of blood flow by Doppler ultrasound [Abstract]. Br J Radiol 1986; 59: 838.

16 Rowell LB. Human cardiovascular adjustments to 
exercise and thermal stress. Physiol Rev 1974; 54: 75-159.

17 Jones NL, Campbell EJ. Clinical exercise testing. Philadelphia: Saunders, 1982: 248.

18 Scher AM, Ohm WW, Bumgarner K, Boynton R, Young AC. Sympathetic and parasympathetic control of heart rate in the dog, baboon and man. Fed Proc 1972; 31: 1219-25.
19 Ganong WF. Review of medical physiology. Los Altos, California: Lange Medical Publications, 1983: 509.

20 Blackmon JR, Rowell LB, Kennedy RD, Twiss RD, Conn RD. Physiological significance of maximal oxygen intake in pure mitral stenosis. Circulation 1967; 36: 497510 . 